\title{
Advances of Optofluidic Microcavities for Microlasers and Biosensors
}

\author{
Zhiqing Feng ${ }^{1}$ and Lan Bai ${ }^{2, *}$ \\ 1 College of Physics and Materials Engineering, Dalian Nationalities University, Dalian 116600, China; \\ fzq@dlnu.edu.cn \\ 2 College of Mechanical and Electronic Engineering, Dalian Nationalities University, Dalian 116600, China \\ * Correspondence: bailan@dlnu.edu.cn
}

Received: 29 January 2018; Accepted: 6 March 2018; Published: 9 March 2018

\begin{abstract}
Optofluidic microcavities with high $Q$ factor have made rapid progress in recent years by using various micro-structures. On one hand, they are applied to microfluidic lasers with low excitation thresholds. On the other hand, they inspire the innovation of new biosensing devices with excellent performance. In this article, the recent advances in the microlaser research and the biochemical sensing field will be reviewed. The former will be categorized based on the structures of optical resonant cavities such as the Fabry-Pérot cavity and whispering gallery mode, and the latter will be classified based on the working principles into active sensors and passive sensors. Moreover, the difficulty of single-chip integration and recent endeavors will be briefly discussed.
\end{abstract}

Keywords: microcavities; optofluidic dye lasers; whispering gallery modes; biosensors

\section{Introduction}

In recent years, optofluidic microcavities have been developed, becoming a key element of microfluidic platforms. Many kinds of microcavities with high $Q$ value and small mode volume have been obtained by using microfabrication technology [1-9] thanks to their excellent light confinement for a long time in a small volume. They enjoy a significant enhancement of light-matter interaction and narrow resonance linewidth, making them favorable for optofluidic microlasers and biochemical sensing applications.

Depending on the light confinement mechanism, the microcavities are generally divided into two categories: Fabry-Pérot (FP) cavities and whispering gallery mode (WGMs) cavities. The materials can be optical fibers, microcapillaries, polymers, silicon or glass substrates. As illuminated in Figure 1, there are usually several common FP microcavities, as defined by their geometric shapes: plane-plane mirror type (PPFP), concave-concave mirror type (CCFP) and plane-concave mirror type (PCFP). Figure 2 shows more kinds of WGM microcavities, including microring, microdisk, microtoroid, microsphere, microbubble and microbottle.

Optofluidic dye lasers are formed by integrating microcavities and gain medium into proper microfluidic circuits or devices. Lots of gain media have been used, such as dyes, quantum dots, rare earth ions, labeled-DNA, fluorescent proteins, chlorophyll solutions, etc. As miniaturized light sources, the optofluidic dye lasers have the merits of low threshold and high $Q$ factor. In addition, they have made significant advances in other aspects such as full bio-compatibility, mode selecting between single and multi-mode, lasing wavelength tunability, and so on. As biochemical sensing elements, the optofluidic lasers usually obtain much higher sensitivity than traditional detecting techniques [10-17]. For sensing applications, they are also described as active resonator sensors. 

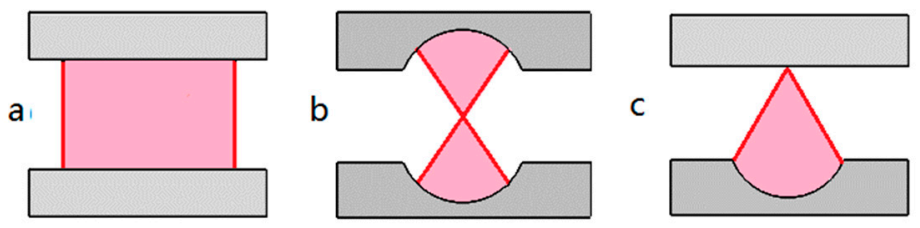

Figure 1. Three configurations of Fabry-Pérot (FP) microcavity, (a) plane-plane mirror type (PPFP). (b) concave-concave mirror type (CCFP). (c) plane-concave mirror type (PCFP).

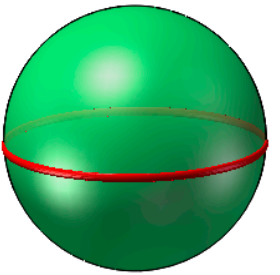

d

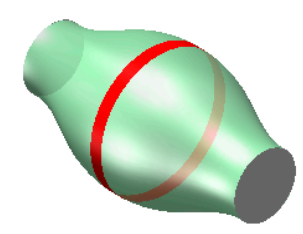

b

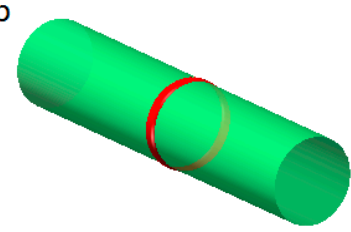

$\mathrm{e}$

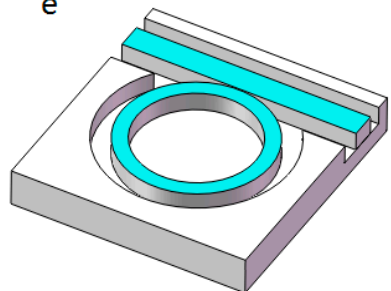

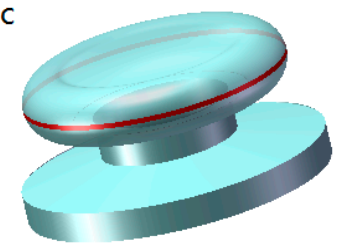

f

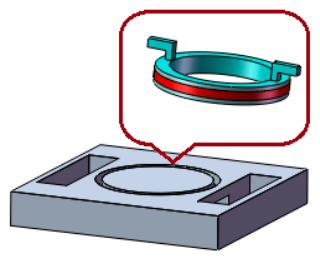

Figure 2. Classical configurations of whispering gallery mode (WGM)-based microcavities. (a) Microsphere; (b) cylindrical ring; (c) microdisk or microtoroid; (d) microbottle; (e) monolithic solid core microring; (f) monolithic liquid core microring.

Optofluidic microcavities can also be worked as passive resonator sensors without gain medium. Recent research has mainly focused on the WGM-based resonators [18-27]. The sensing ability of WGM resonators is characterized by the figure of merit using the $\mathrm{Q}$-factor value to mode volume ratio $(\mathrm{Q} / \mathrm{V})$. The sensitivity can be improved by increasing the $\mathrm{Q}$ value or decreasing the resonators' mode volume. Through ultrafine laser processing, many microscale resonators have been fabricated, and their detection limits have been successfully reduced down to several $\mathrm{kDa}$ molecular weight for single particles [19-25].

This article is not the first to review the topic of optofluidic microcavities. In 2010, Y. Chen gave an in-depth review on the physical theory and the development status of optofluidic microcavities [28]. However, the research of optofluidic microcavities has made substantial progress since then, and many inspiring studies have emerged. It is now a good time to update the latest research progress of optofluidic microcavities in two application areas: optofluidic dye lasers and microcavity-based biosensors.

\section{Optofluidic Microcavities for Dye Lasers}

\subsection{Fabry-Pérot Cavity Dye Lasers}

The FP cavities are easy to fabricate. For example, optical fiber end faces or glass slides can be used to constitute the PPFP cavity; microscale concaves (or concave arrays) made by laser machining on planar substrates can form the PCFP cavity [29-35]. Figure 3 shows the PCFP cavity array structure made by Wang [29]. By depositing the Bragg reflection dielectric layers, the $Q$ value was enhanced to $5.6 \times 10^{5}$. When the cavity length was $31 \mu \mathrm{m}$, the laser threshold was lowered to $0.09 \mu \mathrm{J} \cdot \mathrm{mm}^{-2}$. When the cavity length was shortened to $8 \mu \mathrm{m}$, the excitation threshold was increased to $0.5 \mu \mathrm{J} \cdot \mathrm{mm}^{-2}$, and single mode lasing was observed at $599 \mathrm{~nm}$. The Lahoz group reported another simple design of a 
PPFP dye laser [31] which could be excited by a low-power continuous-wave (CW) laser diode with the threshold of $1.3 \mu \mathrm{J} \cdot \mathrm{mm}^{-2}$. As a sensor, it could be operated in laser mode or fluorescence mode by changing the excitation laser intensity.
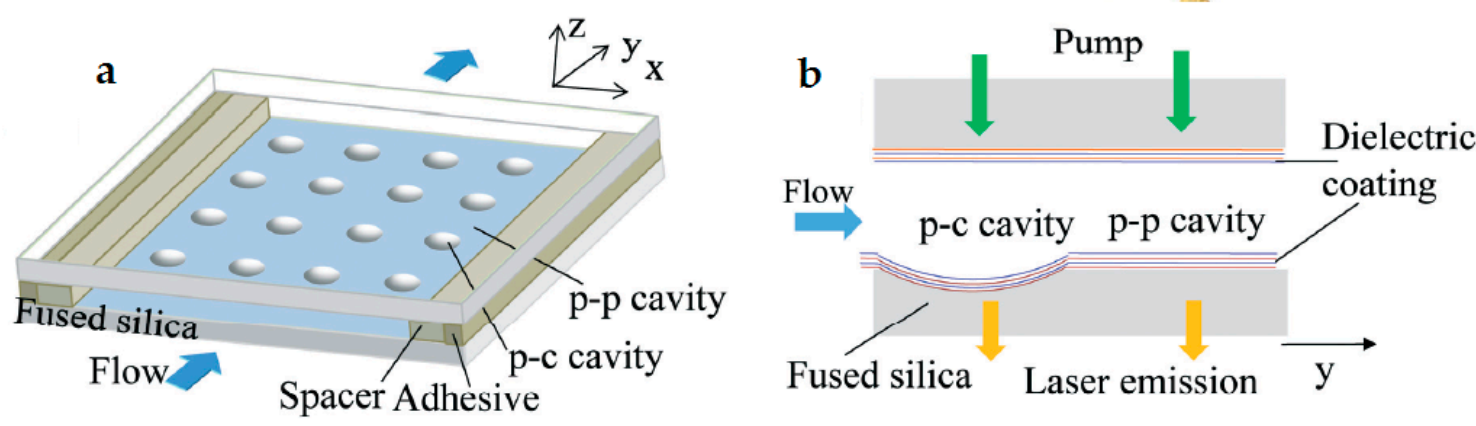

Figure 3. (a) Schematic of the optofluidic laser array based on the PCFP and PPFP cavities. (b) Details of the experimental setup employing both the PCFP and the PPFP cavity on the same fused silica chip [29].

Gerosa [33] constructed all-fiber high-repetition-rate microfluidic dye lasers by welding the optical fibers and the capillary tubes. The excitation threshold was about $1 \mu \mathrm{J}$ by using $532-\mathrm{nm}, 300-\mathrm{ps} 1-\mathrm{kHz}$ pulse laser. The structure is illuminated in Figure 4. Some key features of the FP cavity dye lasers are listed in Table 1.
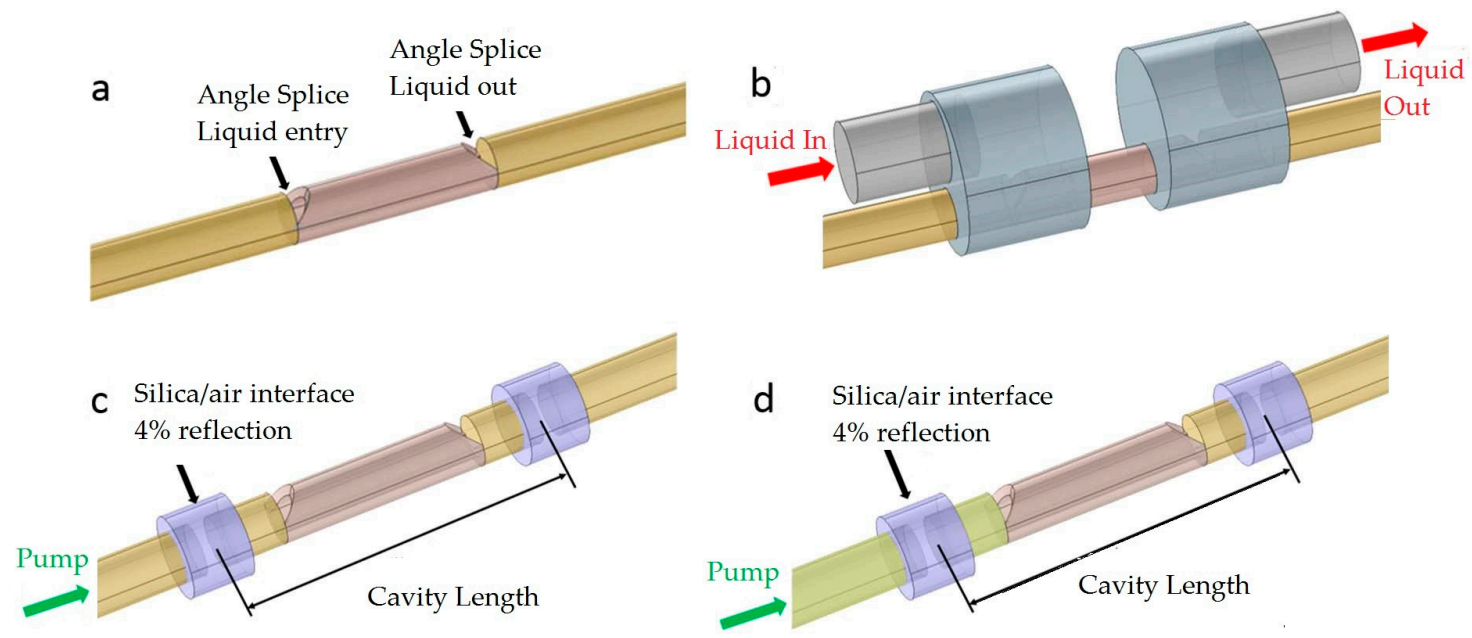

Multimode Fiber

SMF-28

$80 / 56 \mu \mathrm{m}$ Capillary

$1 \mathrm{~mm}$ Glass Tube

Metal Tube Anti-Fiber

Figure 4. Device schemes of the all-fiber high-repetition-rate microfluidic dye lasers. (a) Angle-cleaved capillary spliced to conventional fibers, allowing for liquid flow; (b) a whole device, including the pressure cells formed by glass tubes and their connection to liquid reservoirs via metal tubes; (c) multimode laser cavity, including air gaps for the feedback via Fresnel reflection; (d) few-mode laser cavity with similar air gaps but with a small-core fiber (SMF-28) in one side to provide modal filtering. Anti-fiber is the capillary (inner diameter $128 \mu \mathrm{m}$ ) used to generate the air gaps [33]. 
Table 1. List of the optofluidic lasers based on the Fabry-Pérot microcavities.

\begin{tabular}{|c|c|c|c|c|c|c|c|}
\hline Ref. & $\begin{array}{c}\text { Cavity } \\
\text { Configuration }\end{array}$ & $\begin{array}{c}\text { Cavity } \\
\text { Length }(\mu \mathrm{m})\end{array}$ & Q-Factor & $\begin{array}{l}\text { Threshold } \\
\left(\mu \mathrm{J} \cdot \mathrm{mm}^{-2}\right)\end{array}$ & Lasing Mode & Gain Materials & $\begin{array}{c}\text { Cavity } \\
\text { Materials }\end{array}$ \\
\hline [29] & PCFP & 31 & $5.6 \times 10^{5}$ & 0.09 & Mutlimode & R6G & $\begin{array}{l}\text { Fused Silica } \\
\text { substrate }\end{array}$ \\
\hline [30] & PCFP & 39 & $4 \times 10^{5}$ & 0.13 & Mutlimode & R6G & $\begin{array}{l}\text { Fused Silica } \\
\text { substrate }\end{array}$ \\
\hline [32] & PPFP & 165 & & 1.3 & Mutlimode & $\begin{array}{l}\text { IgG-Atto } 488 \\
\text { complex }\end{array}$ & $\begin{array}{l}\text { Fused Silica } \\
\text { plate }\end{array}$ \\
\hline [33] & PPFP & $\sim 10,000$ & & 1 & Mutlimode & Rh640 & Fiber, caplilary \\
\hline
\end{tabular}

\subsection{WGM Dye Lasers}

The WGM dye lasers are obtained by the combination of a liquid or solid state gain medium and WGM microresonators. If the medium around the microresonator has positive optical gain, the evanescent wave of the WGMs would interact with the medium to generate WGM laser emission. Various forms of resonators have been demonstrated, such as microring, microsphere, microbubble, microdisc, microtoroid, and microbottle [36-62]. Cylindrical and planar microring are more popular due to their simple configurations which confine the photon propagation in the quasi-two-dimensional space. Recently, a solid or hollow microbottle based on microcylinder or microcapillary structures has been proposed for the WGM lasers. The advantage of the microbottle structure is that it has multiple non-degenerated modes along the axis of the revolution, which are convenient for modes selection. Single-mode lasing can be realized by spatial pump engineering [42-44]. Here, we list in Table 2 the main features of the recently proposed WGM dye lasers.

Table 2. List of the optofluidic lasers based on the WGM microcavities.

\begin{tabular}{|c|c|c|c|c|c|c|c|}
\hline Ref. & $\begin{array}{c}\text { Cavity } \\
\text { Configuration }\end{array}$ & $\begin{array}{c}\text { Cavity } \\
\text { Length }(\mu \mathrm{m})\end{array}$ & Q-Factor & Threshold & Lasing Mode & Gain Materials & $\begin{array}{c}\text { Cavity } \\
\text { Materials }\end{array}$ \\
\hline [37] & $\begin{array}{l}\text { Cylindrical } \\
\text { ring resonator }\end{array}$ & $\sim 410$ & $2.6 \times 10^{6}$ & $5.9 \mu \mathrm{J} / \mathrm{mm}^{2}$ & Single mode, $386.75 \mathrm{~nm}$ & LD390 & $\begin{array}{l}\text { Microcapillary, } \\
\text { glass solid } \\
\text { cylinder }\end{array}$ \\
\hline [38] & $\begin{array}{l}\text { Cylindrical } \\
\text { ring resonator }\end{array}$ & $59.9-90.9$ & & 16-44 nJ/pulse & $\begin{array}{l}\sim 10 \text { nm tunable range, } \\
\text { axial pumping }\end{array}$ & R6G, RhB & $\begin{array}{l}\text { Hollow core } \\
\text { microstructured } \\
\text { fiber }\end{array}$ \\
\hline [39] & $\begin{array}{l}\text { Cylindrical } \\
\text { ring resonator }\end{array}$ & 17.4 & & $664 \mathrm{~nJ} \cdot \mathrm{mm}^{-2}$ & $\begin{array}{l}\text { Single longitudinal } \\
\text { mode, lateral pumping }\end{array}$ & R6G & $\begin{array}{l}\text { Hollow core } \\
\text { microstructured } \\
\text { fiber }\end{array}$ \\
\hline [40] & $\begin{array}{l}\text { Cylindrical } \\
\text { ring resonator }\end{array}$ & 157,393 & & $\begin{array}{l}\text { Several tens } \\
\mu \mathrm{J} / \mathrm{mm}^{2}\end{array}$ & $\begin{array}{l}\text { Mutlimode, } \\
520-560 \mathrm{~nm}\end{array}$ & Ribo-flavin & Microcapillary \\
\hline [41] & $\begin{array}{l}\text { Cylindrical } \\
\text { ring resonator }\end{array}$ & 157 & 6000 & $1.2 \mu \mathrm{J}$ & $\begin{array}{l}\text { Mutlimode, } \\
600-615 \mathrm{~nm}\end{array}$ & Nile red dye & $\begin{array}{l}\text { Microcapillary, } \\
\text { polymer }\end{array}$ \\
\hline [48] & $\begin{array}{l}\text { Cylindrical } \\
\text { ring resonator }\end{array}$ & 393 & $\sim 106$ & $23 \mu \mathrm{J} / \mathrm{mm}^{2}$ & $\begin{array}{l}\text { Mutlimode, } \\
510-520 \mathrm{~nm}\end{array}$ & eGFP & Bare SM-28 fiber \\
\hline [2] & $\begin{array}{l}\text { Monolithic } \\
\text { liquid-core } \\
\text { ring resonator }\end{array}$ & 534 & $3.3 \times 104$ & $15 \mu \mathrm{J} / \mathrm{mm}^{2}$ & $\begin{array}{l}\text { Mutlimode, } \\
570-580 \mathrm{~nm}\end{array}$ & R6G & Glass \\
\hline [42] & Microbottle & 9-19 & & $10-20 \mu \mathrm{W} / \mathrm{mm}^{2}$ & $\begin{array}{c}\text { Single mode, } \\
580-620 \mathrm{~nm} \text {, tunable }\end{array}$ & R6G & $\begin{array}{l}\text { Microfiber, } \\
\text { polymer }\end{array}$ \\
\hline [4] & Microbottle & 534 & & $\sim 3.6 \mathrm{~mW}$ & $\begin{array}{c}\text { Multimode, } \\
1530-1540 \mathrm{~nm}\end{array}$ & $\begin{array}{l}\text { Er: Yb doped } \\
\text { glass }\end{array}$ & glass \\
\hline [51] & Droplet & 323 & 5800 & & $\begin{array}{l}\text { Multimode, } \\
590-610 \mathrm{~nm}\end{array}$ & R6G & $\begin{array}{l}\text { Dichloro-methane } \\
\text { and epoxy resin }\end{array}$ \\
\hline
\end{tabular}

In the WGM lasers, the carrier utilizes the hollow microstructured fibers, the microcapillaries or the planar microrings on chips, and the gain medium liquid is filled in or flowed through. In some other designs, the dye-doped polymer is coated on the inner or outer wall of resonator to form the 
microring resonator dye lasers using the side or axial pumping. The cavity length of cylindrical resonators can be further reduced by tapering.

In general, the laser output of the microring resonator lasers is spatially divergent. By the WGM mode-coupling between the lasing resonator and another solid cylinder resonator, the emission direction could be limited to a certain range, thus forming the directional emission. As shown in Figure 5, Tu reported the uses of thin-walled capillary and solid cylinder to construct the coupled ring resonator dye laser [37]. Ultraviolet single-frequency laser emission was generated with a pump threshold of $5.9 \mu \mathrm{J} \cdot \mathrm{mm}^{-2}$. The laser emission was mainly in two directions with a divergence of $10.5^{\circ}$. The single mode lasing of different power was realized by changing the position of the two resonators.

In another work, Lee [40] used riboflavin water solution as the gain medium to construct the microring optofluidic lasers based on microcapillary tube and optical fiber, respectively. Riboflavin has good biocompatibility as compared to other organic dyes. Multimode lasing at 520-560 $\mathrm{nm}$ band was obtained by side pumping of optical parametric oscillator (OPO) laser. The threshold was several tens to one hundred $\mu \mathrm{J} \cdot \mathrm{mm}^{-2}$.

In addition to the liquid gain media, the solid gain layer was also proposed by coating dye-doped polymer on the surface of microcapillary resonators and was first demonstrated by Francois [41]. Usually, the laser features vary with the thickness of gain layer and the solution refractive index in the capillary. The proper thickness range of polymer was $600-800 \mathrm{~nm}$. The multimode lasing of 590-630 $\mathrm{nm}$ was generated under the excitation of $532 \mathrm{~nm}$ laser by the side pumping. The excitation threshold was lowered to $1.2 \mu \mathrm{J}$ (thickness of $800 \mathrm{~nm}$ ) and $16 \mu \mathrm{J}$ (thickness of $600 \mathrm{~nm}$ ), respectively.

Hollow-core micro-structured optical fibers have a smaller scale than the microcapillaries, and have thus lower internal connection losses. They are often used as miniaturized resonators by tapering. The cavity length is different along the axis. This feature could be applied to frequency tuning. Recently, Liu group [38] proposed a tunable microring dye laser, in which RhB and R6G were used as gain media. The threshold of $16-44 \mathrm{~nJ} /$ pulse was obtained by the axial pumping. The tuning range was $10 \mathrm{~nm}$. Besides, Yu [39] constructed a single longitudinal mode optofluidic microring laser by the hollow microstructure fiber. The effective cavity length was about $109.3 \mu \mathrm{m}$. The dye fluid was injected into the hollow fiber. The threshold was lowered to $664 \mathrm{~nJ} \cdot \mathrm{mm}^{-2}$ by the side pumping. Different dyes were used for laser emission of different wavelengths. 
a
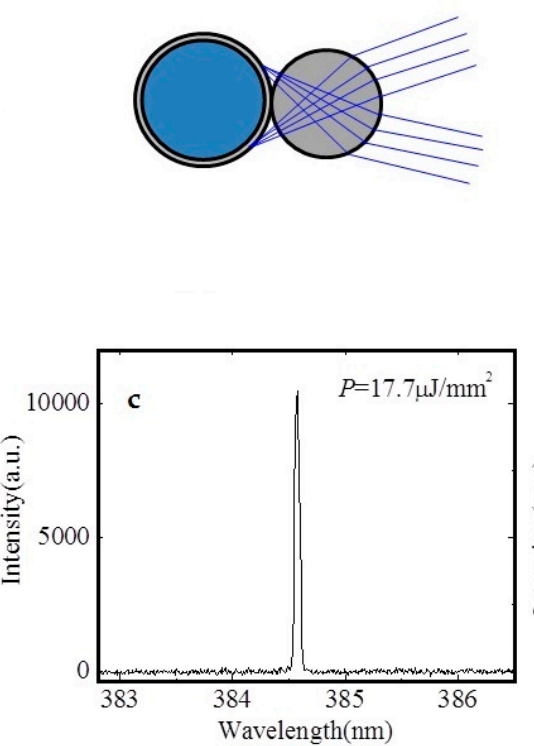
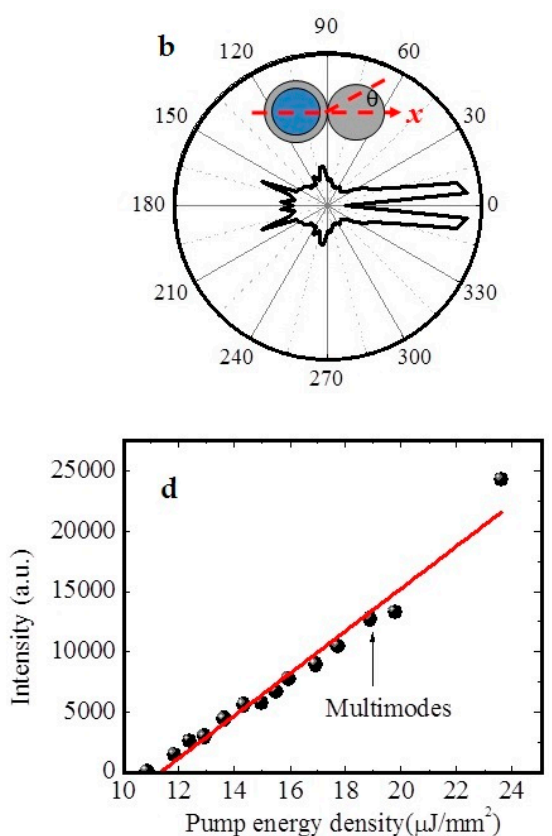

Figure 5. (a) Schematic of the focused light rays from the cylinder. (b) Far-field distribution of light. (c) Single wavelength lasing under lower pump power. (d) Plot of the relation between the output intensity and pump energy density [37].

In general, the planar liquid-core microring resonator requires a liquid-core waveguide channel to connect to the liquid microring resonator channel to transport the gain medium, which inevitable results in a decrease of the Q-factor. By using the three-dimensional (3D) direct-writing of the femtosecond laser, the gain medium inlet and outlet channels could be designed in the non-WGM area and the high Q-factor could be maintained using the 3D pipeline design. Monolithic microring laser on glass substrate was first reported by Fan's group [2]. The ring cavity had the inner radius, the outer radius and depths of $150 \mu \mathrm{m}, 170 \mu \mathrm{m}$ and $40 \mu \mathrm{m}$, respectively. As shown in Figure 6, R6G dye was dissolved in a quinoline solution with refractive index 1.62 to act as the gain medium. It was pumped by nanosecond pulses which were generated by a 532-nm optical parametric oscillator (OPO) laser. Since the fluid refractive index was bigger than the glass, the WGM wave was mainly confined in the fluid close to the outer edge. The lasing spectrum was multimode and the lasing threshold was approximated $15 \mu \mathrm{J} \cdot \mathrm{mm}^{-2}$.

a

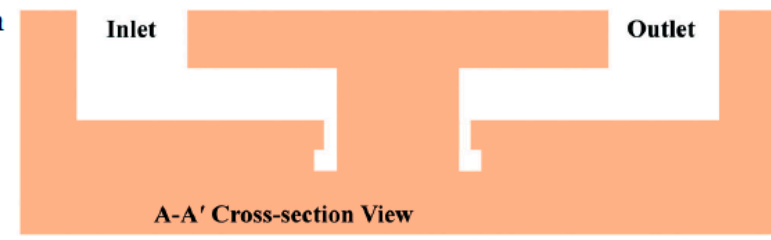

b

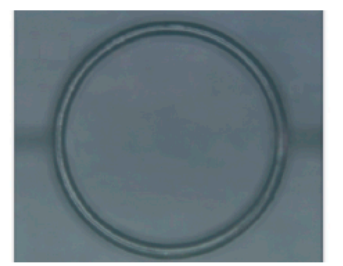

c

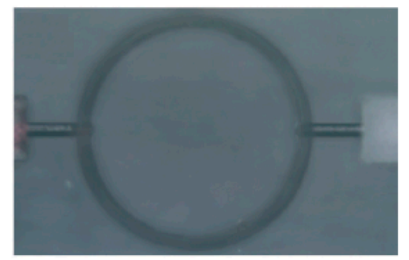

Figure 6. (a) Cross-sectional view of the monolithic optofluidic ring resonator; $(\mathbf{b}, \mathbf{c})$ Micrographs of the bottom and the top by focusing on the ring and the fluid delivery channel, respectively [2]. 
The WGM dye lasers based on the microbottle have multi-wavelengths distributed along the axis. A single WGM lasing mode could be obtained by the spatial modulation approach of pumping, which may result from the laser-interference excitation field. Gu's group [42] proposed WGM lasing in dye-doped polymer microbottle resonators, as shown in Figure 7. The pump energy distribution profile along the axis could be rearranged by adjusting the angle between the two excitation beams. The lasing might be single mode by tuning the space of the fringes along the axis and the frequency could be tuned by applying a tensile stress along the fiber axis.

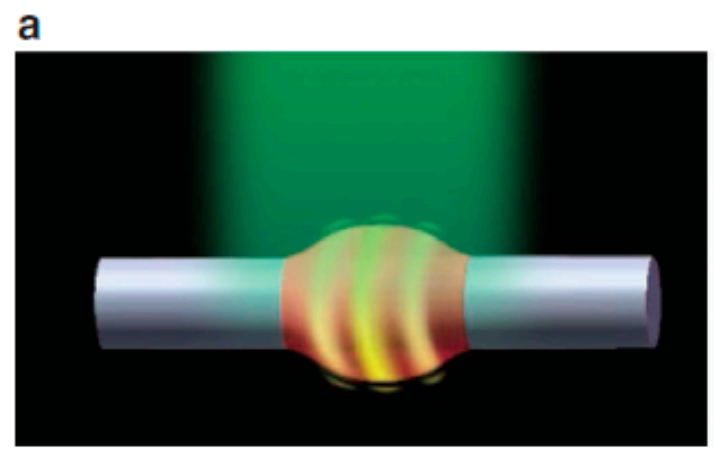

Uniform pump

b

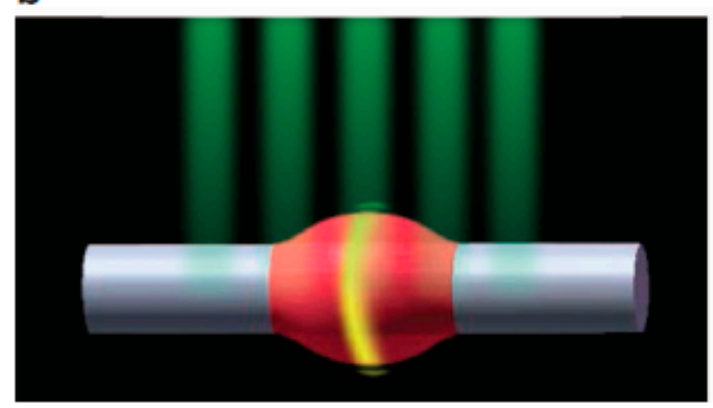

Engineered pump

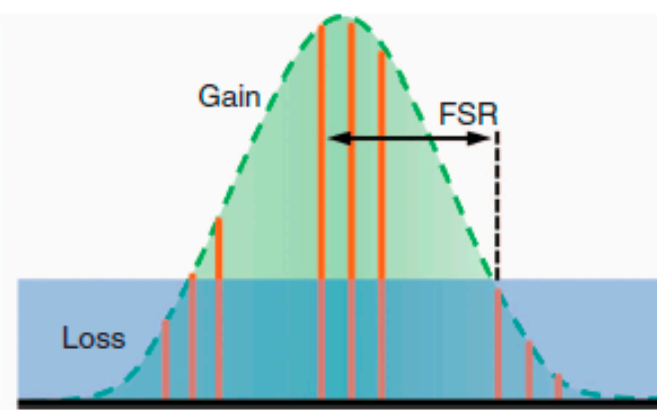

Multimode lasing

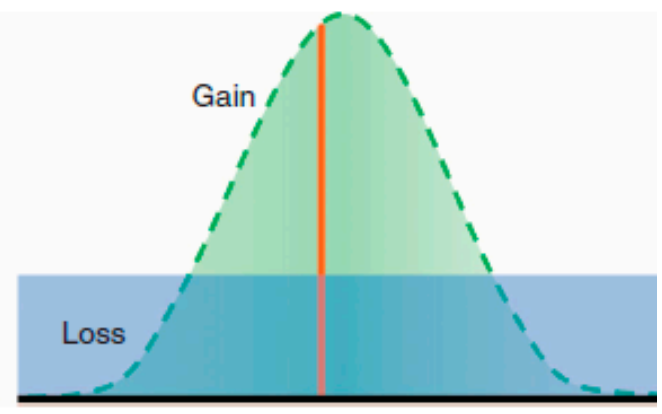

Single-mode lasing

Figure 7. WGM dye laser based on the microbottle structure. (a) Uniform pump and multimode lasing; (b) modulation pumping and single mode lasing [42].

Optofluidic lasers with a single molecular layer of gain was first reported by Fan's group [48,49]. The gain layers used enhanced green fluorescent protein (eGFP), dye-labeled bovine serum albumin (BSA) and dye-labeled DNA, and were assembled on the surface of ring resonators by the surface immobilization biochemical methods. This is a very interesting work for high sensitivity surface bio-detection.

The immiscible dye droplets suspended in the solution are excellent disk-like optical resonators. They also produce lasing output under proper pumping and can be tuned by the solution interfacial tension. Yang [51] used the inkjet print technology to inject a gain medium solution to float on the water to form a fully liquid WGM microlaser. The tension was changed by the concentration of soap water.

\section{Optofluidic Microcavities for Biosensors}

The physical mechanism of the bio-sensing using the optical microcavities is that the electric field distribution is changed by the variation of refractive index of surrounding medium. The redistribution of electric field would alter the cavities' resonance mode, which in turn would vary the time (or frequency) domain features of signal light, such as a resonant peak shift, resonant mode splitting, broadening, and intensity variation, etc. By detecting these optical features, the concentration of species can be obtained, which is highly related to the refractive index of sample solution. Especially for the WGM cavities with high $Q$ factor, standing waves are formed around the 
ring due to the long light travelling time (or distance). Even if a single bio-particle of nanoscale is locally attached to the cavities' surface, it would also rearrange the electric field distribution because of highly enhanced light-particle interaction. Recently, much research attention has been put on the WGM-based detection of single particles, such as virus, DNA and single proteins [19-25,63-79]. Some reviews had made detailed descriptions of the theories and the recent biosensing applications of optical microresonators $[27,28,67,68]$. Here, we will just review the bio-sensing from the two supplementary aspects: microcavity-based active biosensing and microcavity-based passive biosensing.

\subsection{Microcavity-Based Active Biosensing}

When the target concentration is extremely low, the traditional fluorescent intensity-based bio-detecting methods hardly work due to the low signal intensity and various types of noises. For example, enzyme-linked immunosorbent assay (ELISA) kits rely on the intensity of fluorescence generated from the product of the enzyme-substrate reaction so as to quantify the targets attached to the solid surface of ELISA kits. The detection limits are usually sub- $\mu \mathrm{g} \cdot \mathrm{L}^{-1}$ for most targets' bulk solutions and are hard to decrease further due ro the influences of nonspecific bindings, the auto-fluorescence of materials and leakage of excitation light. To improve the detection limit of ELISA, Fan's group [12] incorporated the PPFP cavities into the ELISA kits, in which fluorescence was confined and resonated to lasing by detecting the lasing onset time to obtain the concentration of interleukin- 6 solutions. The threshold of the laser was below $320 \mu \mathrm{J} \cdot \mathrm{mm}^{-2}$ using the 532-nm OPO pulsed laser pumping. The detection limit was reduced to $1 \mathrm{fg} \cdot \mathrm{mL}^{-1}$ and the dynamic range was extended to $10^{6}$. A similar detection method was applied to the photocatalytic reaction by the same group [13], which constructed an optofluidic catalytic laser for ultra-sensitive sulfide ion detection.

Besides this, the fluorescence resonance energy transfer (FRET) process can be incorporated into the microcavity to form a laser-based sensing platform, which would greatly improve the sensitivity of bio-sensing $[15,16]$. More descriptions of the theories of FRET laser-based sensing can be also found in [17].

Moreover, Ren $[63,64]$ proposed an optofluidic laser for high-sensitivity and low-detection-limit sensing of refractive index, which obtained the sensitivity of $3874 \mathrm{~nm} / \mathrm{RIU}$ and the noise equivalent detection limit of $2.6 \times 10^{-6}$ RIU. Zhang [65] improved the refractive index sensitivity of the microring laser by two orders of magnitude via the strong coupling between the ring laser and the fluidic microtube.

\subsection{Microcavity-Based Passive Biosensing}

For the passive bio-sensors based on microcavities, the researchers mainly focused on WGM-based resonators due to the powerful detection abilities of surface bio-reactions. Different configurations of resonators have been implemented for label-free bio-sensing, such as cylindrical ring, bottle, bubble-like, disc or toroidal, and planar liquid core ring [19-26]. As the passive sensors, no gain medium is needed and thus no fluorescence or lasing is produced. An external light source (white source or tunable laser) is used to couple photons into the cavities by the taper fiber or the waveguide. By monitoring the shift or splitting the resonant peaks of transmission spectra, analyte concentration or molecule attaching can be detected [69-84]. As the optical confinement elements, the cavities with high $Q$ factor would greatly enhance the light-matter interaction and would result in high sensitivity. However, there are some potential problems such as light source fluctuation, temperature variation, large background caused by the low couple efficiency of excitation, detector noises, etc. All of these factors would deteriorate the detection limit significantly.

Hybrid microcavities have been reported to utilize the plasmon resonances to further enhance the light-matter interaction [85-89]. Advanced signal processing techniques such as self-reference differential detection, frequency locking (or phase locking detection) are developed to improve the signal and noise ratio (SNR) [90-98]. The detection limit is reduced to the level of $\sim 5 \mathrm{kDa}$ for a single bio-particle. An excellent example of this kind of work was reported by Zhang [91], who developed a 
self-referenced differential mode sensing method. It used two resonant modes in the same microbottle resonator to reduce the measurement noises from the exciting source fluctuation. The detection limit of $10 \mathrm{fg} \cdot \mathrm{mL}^{-1}$ for bovine serum albumin molecules was obtained. Su [94] used the laser frequency locking technique to improve the SNR of microtoroid resonators, obtaining the detection of single nanoparticles of $2.5 \mathrm{~nm}$ in radius and $15.5 \mathrm{kDa}$ molecular weight. In addition to the detection of liquid concentration and single particles, these sensors could also be used for gas sensing applications [99,100].

Although optofluidic microcavities based on WGM have great potential in sensing, the integration on a single chip remains a big challenge. For example, high-quality 3D microdisk (or microtoroid) resonators could be easily fabricated by laser processing on glass or silicon substrates, but the photonic waveguides that are necessary for delivering the probe light are hard to fabricate. Taper fibers are usually applied and more extra processing is needed. Yet the uncertainty regarding the geometric parameters of taper fiber and the gap between them are severe hindrances to bulk production. Resonators made by microcapillaries or hollow fibers are also difficult to integrate on a monolithic chip owing to their large sizes and structural fragility. Recently, Schmidt's group [101] has developed an innovative approach called lab-in- $a$-tube, which integrates numerous rolled-up components into a single device on a chip. Figure 8 shows a $\mathrm{TiO}_{2}$ microtubular optical resonator as a result of the rolling-up of a 2D planar membrane deposited on the substrates due to the surface stress. In addition, the resonator is integrated with vertical-sited SU-8 polymer waveguide. The geometric parameters of microtube, the waveguide and the gap between them were well defined and controllable at nanoscale. The test results showed that the resonators had good sensing performance and excellent optical coupling efficiency with an extinction ratio of $32 \mathrm{~dB}$ over the communication band. Other materials such as $\mathrm{SiO}_{2}$ was also developed by the same group [102,103]. These studies made an important contribution to the research of optofluidic monolithic integration.
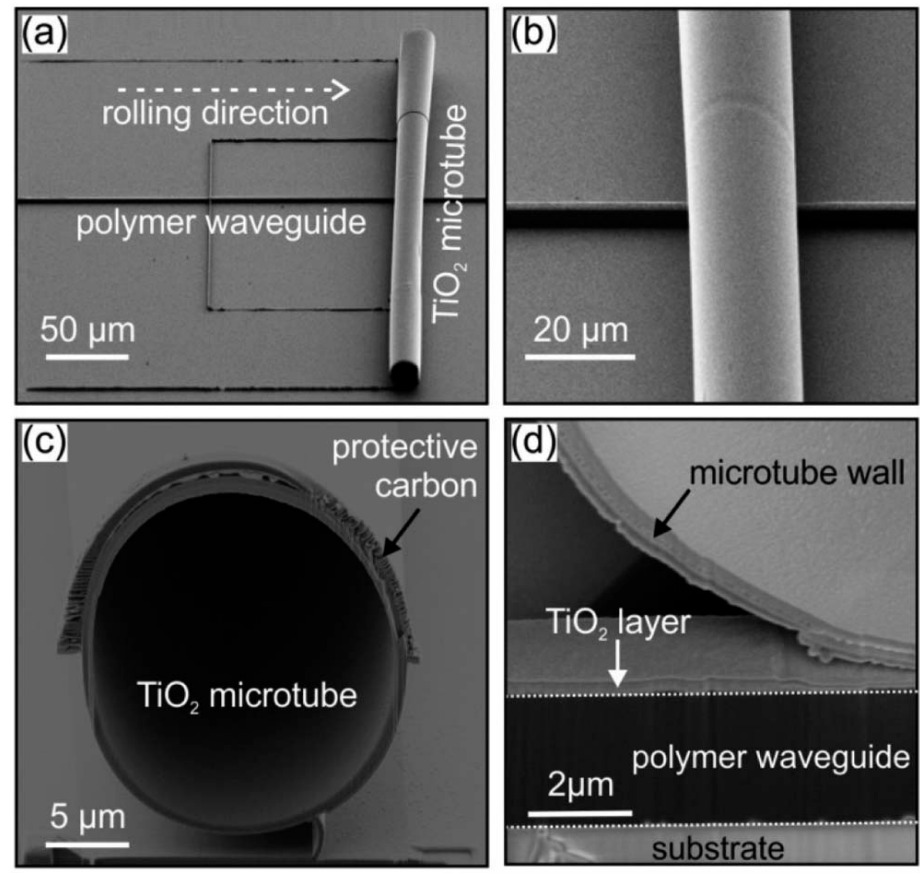

Figure 8. Lab-in-a-tube system made of rolled-up $\mathrm{TiO}_{2}$ microresonators integrated with polymer waveguides. (a) Microtube was rolled-up by a U-shaped pattern. (b) Close-up view of the tube that is connected tightly with the polymer waveguide to ensure optimal optical coupling. (c) Compact winding layers of the tube wall were revealed by a FIB cut with the protection of a carbon layer. (d) The FIB cut image at the waveguide revealed the compact tube wall in the vicinity of the polymer waveguide [101]. 


\section{Conclusions}

Optofluidic microcavities have found wide applications and are still expanding their application areas rapidly. Here, we have summarized the recent progress in the areas of microlasers and biosensors. Generally, the optofluidic microlasers are developing toward high Q factors with a low threshold, small volume, easy mode controllability and wide tunability. In addition, the high performance of microresonators improves the light-matter interaction and thus greatly enhances the sensing abilities and the scope of applications. By means of process improvement, structure integration and detection method innovation, new microcavity devices with higher performance are presented continuously. It is expected that more practical devices will be developed for lasers, biosensors and other applications.

Acknowledgments: This project is supported by the Educational Committee Foundation of Liaoning Province (L2015126).

Author Contributions: Zhiqing Feng collected and analyzed the data, prepared the spreadsheets and figures and drafted the manuscript. Lan Bai conceived and revised the manuscript.

Conflicts of Interest: The authors declare no conflict of interest.

\section{References}

1. Wang, M.; Lin, J.T.; Xu, Y.X.; Fang, Z.-W.; Qiao, L.-L.; Liu, Z.-M.; Fang, W.; Cheng, Y. Fabrication of high-Q microresonators in dielectric materials sing a femtosecond laser: Principle and applications. Opt. Commun. 2017, 395, 249-260. [CrossRef]

2. Chandrahalim, H.; Chen, Q.; Said, A.A.; Dugan, M.; Fan, X. Monolithic optofluidic ring resonator lasers created by femtosecond laser nanofabrication. Land Chip 2015, 15, 2335-2340. [CrossRef] [PubMed]

3. Simoni, F.; Bonfadini, S.; Spegni, P.; Lo, T.S.; Lucchetta, D.E.; Criante, L. Low threshold Fabry-Pérot optofluidic resonator fabricated by femtosecond laser micromachining. Opt. Express 2016, 24, 17416-17423. [CrossRef] [PubMed]

4. Ward, J.M.; Yang, Y.; Chormaic, S.N. Glass-on-glass fabrication of bottle-shaped tunable microlasers and their applications. Sci. Rep. 2016, 6, 25152. [CrossRef] [PubMed]

5. Tada, K.; Cohoon, G.; Kieu, K.; Mansuripur, M.; Norwood, R.A. Fabrication of high-Q microresonators using femtosecond laser micromachining. In Proceedings of the Lasers and Electro-Optics (CLEO), San Jose, CA, USA, 6-11 May 2012; pp. 1-2.

6. Lin, J.; Xu, Y.; Tang, J.; Wang, N.; Song, J.; He, F.; Fang, W.; Cheng, Y. Fabrication of three-dimensional microdisk resonators in calcium fluoride by femtosecond laser micromachining. Appl. Phys. A 2014, 116, 2019-2023. [CrossRef]

7. Lin, J.; Xu, Y.; Fang, Z.; Wang, M.; Song, J.; Wang, N.; Qiao, L.; Fang, W.; Cheng, Y. Fabrication of high-Q lithium niobate microresonators using femtosecond laser micromachining. Sci. Rep. 2015, 5, 8072. [CrossRef] [PubMed]

8. Kosma, K.; Zito, G.; Schuster, K.; Pissadakis, S. Whispering gallery mode microsphere resonator integrated inside a microstructured optical fiber. Opt. Lett. 2013, 38, 1301-1303. [CrossRef] [PubMed]

9. He, F.; Tang, J.; Song, J.; Lin, J.; Liao, Y.; Wang, Z.; Qiao, L.; Sugioka, K.; Cheng, Y. Fabrication of an integrated high-quality-factor (high-Q) optofluidic sensor by femtosecond laser micromachining. Opt. Express 2014, 22, 14792-14802.

10. Lahoz, F.; Martín, I.R.; Walo, D.; Freire, R.; Gil-Rostra, J.; Yubero, F.; Gonzalez-Elipe, A.R. Enhanced green fluorescent protein in optofluidic Fabry-Perot microcavity to detect laser induced temperature changes in a bacterial culture. Appl. Phys. Lett. 2017, 111, 111103. [CrossRef]

11. Floch, J.M.L.; Fan, Y.; Humbert, G.; Shan, Q.; Férachou, D.; Bara-Maillet, R.; Aubourg, M.; Hartnett, J.G.; Madrangeas, V.; Cros, D.; et al. Invited Article: Dielectric material characterization techniques and designs of high-Q resonators for applications from micro to millimeter-waves frequencies applicable at room and cryogenic temperatures. Rev. Sci. Instrum. 2014, 85, 489-493. [CrossRef] [PubMed]

12. Wu, X.; Oo, M.K.; Reddy, K.; Chen, Q.; Sun, Y.; Fan, X. Optofluidic laser for dual-mode sensitive biomolecular detection with a large dynamic range. Nat. Commun. 2014, 5, 3779. [CrossRef] [PubMed] 
13. Gong, C.; Gong, Y.; Khaing Oo, M.K.; Wu, Y.; Rao, Y.; Tan, X.; Fan, X. Sensitive sulfide ion detection by optofluidic catalytic laser using horseradish peroxidase (HRP) enzyme. Biosens. Bioelectron. 2017, 96, 351-357. [CrossRef] [PubMed]

14. Chen, Q.; Liu, H.; Lee, W.; Sun, Y.; Zhu, D.; Pei, H.; Fan, C.; Fan, X. Self-assembled DNA tetrahedral optofluidic lasers with precise and tunable gain control. Lab Chip 2013, 13, 3351-3354. [CrossRef] [PubMed]

15. Özelci, E.; Aas, M.; Jonáš, A.; Kiraz, A. Optofluidic FRET microlasers based on surface-supported liquid microdroplets. Laser Phys. Lett. 2014, 11, 045802. [CrossRef]

16. Chen, Q.; Zhang, X.; Sun, Y.; Ritt, M.; Sivaramakrishnan, S.; Fan, X. Highly sensitive fluorescent protein FRET detection using optofluidic lasers. Lab Chip 2013, 13, 2679-2681. [CrossRef] [PubMed]

17. Aas, M.; Chen, Q.; Jonáš, A.; Kiraz, A.; Fan, X. Optofluidic FRET lasers and their applications in novel photonic devices and biochemical sensing. IEEE J. Sel. Top. Quantum Electron. 2015, 22, 188-202. [CrossRef]

18. Shopova, S.I.; Zhou, H.; Fan, X.; Zhang, P. Optofluidic ring resonator based dye laser. Appl. Phys. Lett. 2007, 90, 221101. [CrossRef]

19. Vollmer, F. Taking detection to the limit-Monitoring single molecule interactions on a label-free microcavity biosensor. IEEE Photonics Technol. Lett. 2014, 28, 4-10.

20. Baaske, M.D.; Foreman, M.R.; Vollmer, F. Single-molecule nucleic acid interactions monitored on a label-free microcavity biosensor platform. Nat. Nanotechnol. 2014, 9, 933-999. [CrossRef] [PubMed]

21. Wu, Y.; Zhang, D.Y.; Yin, P.; Vollmer, F. Ultraspecific and highly sensitive nucleic acid detection by integrating a DNA catalytic network with a label-free microcavity. Small 2014, 10, 2067-2076. [CrossRef] [PubMed]

22. Su, J. Label-free single molecule detection using microtoroid optical resonators. J. Vis. Exp. 2015, 106, e53180. [CrossRef] [PubMed]

23. Swaim, J.D.; Knittel, J.; Bowen, W.P. Detection of nanoparticles with a frequency locked whispering gallery mode microresonator. Appl. Phys. Lett. 2013, 102, 272-274. [CrossRef]

24. Zhu, J.; Özdemir, Ş.K.; He, L.; Chen, D.R.; Yang, L. Single virus and nanoparticle size spectrometry by whispering-gallery-mode microcavities. Opt. Express 2011, 19, 16195-16206. [CrossRef] [PubMed]

25. Li, M.; Wu, X.; Liu, L.; Fan, X.; Xu, L. Self-referencing optofluidic ring resonator sensor for highly sensitive biomolecular detection. Anal. Chem. 2013, 85, 9328-9332. [CrossRef] [PubMed]

26. Choi, C.J.; Belobraydich, A.R.; Chan, L.L.; Mathias, P.C.; Cunningham, B.T. Label-free optofluidic biosensing in microplate, microfluidic, and spot-based affinity capture assays. In Proceedings of the Lasers and Electro-Optics (CLEO) and Quantum Electronics and Laser Science Conference (QELS), San Jose, CA, USA, 16-21 May 2010; Volume 405, pp. 1-2.

27. Fan, X.; Yun, S.H. The potential of optofluidic biolasers. Nat. Methods 2014, 11, 141-147. [CrossRef] [PubMed]

28. Chen, Y.; Lei, L.; Zhang, K.; Shi, J.; Wang, L.; Li, H.; Zhang, X.M.; Wang, Y.; Chan, H.L.W. Optofluidic microcavities: Dye-lasers and biosensors. Biomicrofluid 2010, 4, 043002. [CrossRef] [PubMed]

29. Wang, W.; Zhou, C.; Zhang, T.; Chen, J.; Liu, S.; Fan, X. Optofluidic laser array based on stable high-Q Fabry-Pérot microcavities. Lab Chip 2015, 15, 3862-3869. [CrossRef] [PubMed]

30. Zhang, T.; Zhou, C.; Wang, W.; Chen, J. Generation of low-threshold optofluidic lasers in a stable Fabry-Pérot microcavity. Opt. Laser Technol. 2017, 91, 108-111. [CrossRef]

31. Lahoz, F.; Martín, I.R.; Gilrostra, J.; Olivaramirez, M.; Yubero, F.; Gonzalezelipe, A.R. Portable IR dye laser optofluidic microresonator as a temperature and chemical sensor. Opt. Express 2016, 24, 14383-14392. [CrossRef] [PubMed]

32. Lahoz, F.; Martín, I.R.; Walo, D.; Gil-Rostra, J.; Yubero, F.; Gonzalez-Elipe, A.R. A compact and portable optofluidic device for detection of liquid properties and label-free Sensing. J. Phys. D Appl. Phys. 2017, 50, 215103. [CrossRef]

33. Gerosa, R.M.; Sudirman, A.; Menezes, L.D.S.; Margulis, W.; Matos, C.J.S.D. All-fiber high repetition rate microfluidic dye laser. Optica 2015, 2, 186-193. [CrossRef]

34. Malak, M.; Pavy, N.; Marty, F.; Peter, Y.A.; Liu, A.Q.; Bourouina, T. Micromachined Fabry-Pérot resonator combining submillimeter cavity length and high quality factor. Appl. Phys. Lett. 2011, 98, 211113. [CrossRef]

35. Malak, M.; Gaber, N.; Marty, F.; Pavy, N.; Richalot, E.; Bourouina, T. Analysis of Fabry-Perot optical micro-cavities based on coating-free all-Silicon cylindrical Bragg reflectors. Opt. Express 2013, 21, 2378-2392. [CrossRef] [PubMed]

36. He, L.; Ouml, S.K.; Yang, L. Whispering gallery microcavity lasers. Laser Photonics Rev. 2013, 7, 60-82. [CrossRef] 
37. Tu, X.; Wu, X.; Li, M.; Liu, L.Y.; Xu, L. Ultraviolet single-frequency coupled optofluidic ring resonator dye laser. Opt. Express 2012, 20, 19996-20001. [CrossRef] [PubMed]

38. Li, Z.L.; Zhou, W.Y.; Luo, M.M.; Liu, Y.G.; Tian, J.G. Tunable optofluidic microring laser based on a tapered hollow core microstructured optical fiber. Opt. Express 2015, 23, 10413-10420. [CrossRef] [PubMed]

39. Yu, J.; Liu, Y.; Luo, M.; Wang, Z.; Yang, G.; Zhang, H.W.; Zhang, X.H. Single longitudinal mode optofluidic microring laser based on a hollow-core microstructured optical fiber. IEEE Photonics J. 2017, 9, 7105510. [CrossRef]

40. Lee, W.; Kim, D.B.; Song, M.H.; Yoon, D.K. Optofluidic ring resonator laser with an edible liquid laser gain medium. Opt. Express 2017, 25, 14043-14048. [CrossRef] [PubMed]

41. Francois, A.; Riesen, N.; Gardner, K.; Monro, T.M.; Meldrum, A. Lasing of whispering gallery modes in optofluidic microcapillaries. Opt. Express 2016, 24, 12466-12477. [CrossRef] [PubMed]

42. Gu, F.; Xie, F.; Lin, X.; Linghu, S.; Fang, W.; Zeng, H.; Tong, L.; Zhuang, S. Single whispering-gallery mode lasing in polymer bottle microresonators via spatial pump engineering. Light Sci. Appl. 2017, 6, e17061. [CrossRef]

43. Xie, F.; Gu, F.; Wang, H.; Yao, N.; Zhuang, S.; Fang, W. Single-mode lasing via loss engineering in fiber-taper-coupled polymer bottle microresonators. Photonics Res. 2017, 5, B29-B33. [CrossRef]

44. Lu, Q.; Wu, X.; Liu, L.; Xu, L. Mode-selective lasing in high-Q polymer micro bottle resonators. Opt. Express 2015, 23, 22740-22745. [CrossRef] [PubMed]

45. Grimaldi, I.A.; Berneschi, S.; Testa, G.; Baldini, F.; Conti, G.N.; Bernini, R. Polymer based planar coupling of self-assembled bottle microresonators. Appl. Phys. Lett. 2014, 105, 2012-2016. [CrossRef]

46. Yang, Y.; Ward, J.; Nic Chormaic, S. Quasi-droplet microbubbles for high resolution sensing applications. Opt. Express 2014, 22, 6881-6898. [CrossRef] [PubMed]

47. Li, H.; Suter, J.D.; Reddy, K.; Lee, W.; Fan, X.; Sun, Y. Tunable single mode lasing from an on-chip optofluidic ring resonator laser. Appl. Phys. Lett. 2011, 98, 061103.

48. Chen, Q.; Ritt, M.; Sivaramakrishnan, S.; Sun, Y.; Fan, X. Optofluidic lasers with a single molecular layer of gain. Lab Chip 2014, 14, 4590-4595. [CrossRef] [PubMed]

49. Lee, W.; Chen, Q.; Fan, X.; Dong, K.Y. Digital DNA detection based on a compact optofluidic laser with ultra-low sample consumption. Lab Chip 2016, 16, 4770-4776. [CrossRef] [PubMed]

50. Chen, Y.C.; Chen, Q.; Fan, X. Optofluidic chlorophyll lasers. Lab Chip 2016, 16, 2228-2235. [CrossRef] [PubMed]

51. Yang, S.; Ta, V.D.; Wang, Y.; Chen, R.; He, T.; Demir, H.V.; Sun, H. Reconfigurable liquid whispering gallery mode microlasers. Sci. Rep. 2016, 6, 27200. [CrossRef] [PubMed]

52. Jiang, X.F.; Zou, C.L.; Wang, L.; Gong, Q.; Xiao, Y.F. Whispering-gallery microcavities with unidirectional laser emission. Laser Photonics Rev. 2016, 10, 40-61. [CrossRef]

53. François, A.; Riesen, N.; Ji, H.; Shahraam, A.V.; Monro, T.M. Polymer based whispering gallery mode laser for biosensing applications. Appl. Phys. Lett. 2015, 106, 60-82. [CrossRef]

54. Rui, C.; Ta, V.D.; Han, D.S. Single mode lasing from hybrid hemispherical microresonators. Sci. Rep. 2012, $2,244$.

55. Kryzhanovskaya, N.V.; Maximov, M.V.; Zhukov, A.E. Whispering-gallery mode microcavity quantum-dot lasers. Quantum Electron. 2014, 44, 189-200. [CrossRef]

56. Gu, F.; Zhang, L.; Zhu, Y.; Zeng, H. Free-space coupling of nanoantennas and whispering-gallery microcavities with narrowed linewidth and enhanced sensitivity. Laser Photonics Rev. 2015, 9, 682-688. [CrossRef]

57. Senthil, M.G.; Petrovich, M.N.; Jung, Y.; Wilkinson, J.S.; Zervas, M.N. Hollow-bottle optical microresonators. Opt. Express 2011, 19, 20773-20784. [CrossRef] [PubMed]

58. Aas, M.; Özelci, E.; Jonáš, A.; Fan, X. FRET lasing from self-assembled DNA tetrahedral nanostructures suspended in optofluidic droplet resonators. Eur. Phys. J. Spec. Top. 2014, 223, 2057-2062. [CrossRef]

59. Sun, Y.; Shopova, S.I.; Wu, C.S.; Arnold, S.; Fan, X.D. Bioinspired optofluidic fret lasers via DNA scaffolds. Proc. Natl. Acad. Sci. USA 2010, 37, 16039-16042. [CrossRef] [PubMed]

60. Testa, G.; Persichetti, G.; Bernini, R. Design and optimization of an optofluidic ring resonator based on liquid-core hybrid ARROWs. IEEE Photonics J. 2014, 6, 1-14. [CrossRef]

61. Khalil, D.; Dan, A. Volume refractometry of liquids using stable optofluidic Fabry-Pérot resonator with curved surfaces. J. Micro Nanolithogr. MEMS MOEMS 2015, 14, 045501. 
62. Kushida, S.; Okada, D.; Sasaki, F.; Lin, Z.; Huang, J.; Yamamoto, Y. Lasers: Low-threshold whispering gallery mode lasing from self-assembled microspheres of single-sort conjugated polymers. Adv. Opt. Mater. 2017, 5, 1700123. [CrossRef]

63. Ren, L.; Zhang, X.; Guo, X.; Wang, H.; Wu, X. High-sensitivity optofluidic sensor based on coupled liquid-core laser. IEEE Photonics Technol. 2017, 29, 639-642. [CrossRef]

64. Ren, L.; Wu, X.; Li, M.; Zhang, X.; Liu, L.; Xu, L. Ultrasensitive label-free coupled optofluidic ring laser sensor. Opt. Lett. 2012, 18, 3873-3875. [CrossRef]

65. Zhang, X.; Ren, L.; Wu, X.; Li, H.; Liu, L.; Xu, L. Coupled optofluidic ring laser for ultrahigh-sensitive sensing. Opt. Express 2011, 19, 22242-22247. [CrossRef] [PubMed]

66. Reynolds, T.; Riesen, N.; Meldrum, A.; Fan, X.; Hall, J.M.; Monro, T.; Francois, A. Fluorescent and lasing whispering gallery mode microresonators for sensing applications. Laser Photonics Rev. 2017, 11, 1600265. [CrossRef]

67. Ciminelli, C.; Campanella, C.M.; Dell'Olio, F.; Campanella, C.E.; Armenise, M.N. Label-free optical resonant sensors for biochemical applications. Prog. Quantum Electron. 2013, 37, 51-107. [CrossRef]

68. Wang, Y.; Li, H.; Zhao, L.; Yang, J. A review of droplet resonators: Operation method and application. Opt. Laser Technol. 2016, 86, 61-68. [CrossRef]

69. Chistiakova, M.V.; Shi, C.; Armani, A.M. Label-free, single molecule resonant cavity detection: A double-blind experimental study. Sensors 2015, 15, 6324-6341. [CrossRef] [PubMed]

70. Ruan, Y.; Boyd, K.; Ji, H.; Francois, A.; Ebendorff-Heidepriem, H.; Munch, J.; Monro, T.M. Tellurite microspheres for nanoparticle sensing and novel light sources. Opt. Express 2014, 22, 11995-12006. [CrossRef] [PubMed]

71. He, L.; Ozdemir, S.K.; Zhu, J.; Kim, W.; Yang, L. Detecting single viruses and nanoparticles using whispering gallery microlasers. Nat. Nanotechnol. 2011, 6, 428-432. [CrossRef] [PubMed]

72. Zhu, J.; Zhong, Y.; Liu, H. Impact of nanoparticle-induced scattering of an azimuthally propagating mode on the resonance of whispering gallery microcavities. Photonics Res. 2017, 5, 396-406. [CrossRef]

73. Soria, S.; Berneschi, S.; Lunelli, L.; Nunzi Conti, G.; Pasquardini, L.; Pederzolli, C.; Righini, G.C. Whispering Gallery Mode Microresonators for Biosensing. Adv. Sci. Technol. 2013, 82, 55-63. [CrossRef]

74. Arnold, S.; Keng, D.; Shopova, S.I.; Holler, S.; Zurawsky, W.; Vollmer, F. Whispering gallery mode carousel-A photonic mechanism for enhanced nanoparticle detection in biosensing. Opt. Express 2009, 17, 6230-6238. [CrossRef] [PubMed]

75. Dantham, V.R.; Holler, S.; Barbre, C.; Keng, D.; Kolchenko, V.; Arnold, S. Label-free detection of single protein using a nanoplasmonic-photonic hybrid microcavity. Nano Lett. 2013, 13, 3347-3351. [CrossRef] [PubMed]

76. Zijlstra, P.; Paulo, P.M.; Orrit, M. Optical detection of single non-absorbing molecules using the surface plasmon resonance of a gold nanorod. Nat. Nanotechnol. 2012, 7, 379-382. [CrossRef] [PubMed]

77. Chan, J.; Thiessen, T.; Lane, S.; Gardner, K. Microfluidic detection of vitamin d3 compounds using a cylindrical optical microcavity. IEEE Sens. J. 2015, 15, 3467-3474. [CrossRef]

78. Zhu, H.; Dale, P.S.; Caldwell, C.W.; Fan, X. Rapid and label-free detection of breast cancer biomarker CA15-3 in clinical human serum samples with optofluidic ring resonator sensors. Anal. Chem. 2009, 81, 9858-9865. [CrossRef] [PubMed]

79. Suter, J.D.; Howard, D.J.; Fan, X. Label-free DNA methylation analysis using the optofluidic ring resonator sensor. Biosens. Bioelectron. 2015, 26, 1016-1020. [CrossRef] [PubMed]

80. Zhou, Z.H.; Shu, F.J.; Zhen, S.; Dong, C.H.; Guo, G.C. High-Q whispering gallery modes in a polymer microresonator with broad strain tuning. Sci. China Phys. Mech. Astron. 2015, 58, 1-5. [CrossRef]

81. Chang, L.; Jiang, X.S.; Hua, S.Y.; Yang, C.; Wen, J.M.; Jiang, L.; Li, G.Y.; Wang, G.Z.; Xiao, M. Parity-time symmetry and variable optical isolation in active-passive-coupled microresonators. Nat. Photonics 2014, 8 , 524-529. [CrossRef]

82. Ward, J.; Benson, O. WGM microresonators: Sensing, lasing and fundamental optics with microspheres. Laser Photonics Rev. 2011, 5, 553-570. [CrossRef]

83. Gilardi, G.; Beccherelli, R. Integrated optics nano-opto-fluidic sensor based on whispering gallery modes for picoliter volume refractometry. J. Phys. D Appl. Phys. 2013, 46, 1-9. [CrossRef]

84. Giorgini, A.; Avino, S.; Malara, P.; Natale, P.D.; Gagliardi, G. Fundamental limits in high-Q droplet microresonators. Sci. Rep. 2017, 7, 41997. [CrossRef] [PubMed] 
85. Zhang, M.; Liu, B.; Wu, G.; Chen, D. Hybrid plasmonic microcavity with an air-filled gap for sensing applications. Opt. Commun. 2016, 380, 6-9. [CrossRef]

86. Arbabi, E.; Kamali, S.M.; Arnold, S.; Goddard, L.L. Hybrid whispering gallery mode/plasmonic chain ring resonators for biosensing. Appl. Phys. Lett. 2014, 105, 231107. [CrossRef]

87. Nadgaran, H.; Garaei, M.A. Enhancement of a whispering gallery mode microtoroid resonator by plasmonic triangular gold nanoprism for label-free biosensor applications. J. Appl. Phys. 2015, 118, 043101. [CrossRef]

88. Xiao, Y.F.; Li, B.B.; Jiang, X.; Hu, X.; Li, Y.; Gong, Q. High quality factor, small mode volume, ring-type plasmonic microresonator on a silver chip. J. Phys. B At. Mol. Opt. 2010, 43, 035402. [CrossRef]

89. Bozzola, A.; Perotto, S.; De, A.F. Hybrid plasmonic-photonic whispering gallery mode resonators for sensing: A critical review. Analyst 2017, 142, 883-898. [CrossRef] [PubMed]

90. Santiagocordoba, M.A.; Boriskina, S.V.; Vollmer, F.; Demirel, M.C. Nanoparticle-based protein detection by optical shift of a resonant microcavity. Appl. Phys. Lett. 2011, 99, 073701. [CrossRef]

91. Zhang, X.; Liu, L.; Xu, L. Ultralow sensing limit in optofluidic micro-bottle resonator biosensor by self-referenced differential-mode detection scheme. Appl. Phys. Lett. 2014, 104, 033703. [CrossRef]

92. Tang, T.; Wu, X.; Liu, L.; Xu, L. Packaged optofluidic microbubble resonators for optical sensing. Appl. Opt. 2016, 55, 395-399. [CrossRef] [PubMed]

93. Shang, J.; Dai, H.; Zou, Y.; Chen, X. Detection of low-concentration EGFR with a highly sensitive optofluidic resonator. Chin. Opt. Lett. 2017, 15, 092301. [CrossRef]

94. Su, J.; Goldberg, A.F.; Stoltz, B.M. Label-free detection of single nanoparticles and biological molecules using microtoroid optical resonators. Light Sci. Appl. 2017, 5, e16001. [CrossRef]

95. Lin, G.; Chembo, Y.K. Phase-locking transition in Raman combs generated with whispering gallery mode resonators. Opt. Lett. 2016, 41, 3718-3721. [CrossRef] [PubMed]

96. Deych, L.; Shuvayev, V. Theory of nanoparticle-induced frequency shifts of whispering-gallery-mode resonances in spheroidal optical resonators. Phys. Rev. A 2015, 5, e625-e626. [CrossRef]

97. Bog, U.; Laue, T.; Grossmann, T.; Beck, T.; Wienhold, T.; Richter, B.; Hirtz, M.; Fuchs, H.; Kal, H.; Mappes, T. On-chip microlasers for biomolecular detection via highly localized deposition of a multifunctional phospholipid ink. Lab Chip 2013, 13, 2701-2707. [CrossRef] [PubMed]

98. Li, Q.; Eftekhar, A.A.; Xia, Z.; Adibi, A. A unified approach to mode splitting and scattering loss in high-Q whispering-gallery-mode microresonators. Phys. Rev. A 2013, 88, 8981-8995. [CrossRef]

99. Scholten, K.; Collin, W.R.; Fan, X.; Zellers, E.T. Nanoparticle-coated micro-optofluidic ring resonator as a detector for microscale gas chromatographic vapor analysis. Nanoscale 2015, 7, 9282-9289. [CrossRef] [PubMed]

100. Collin, W.R.; Scholten, K.W.; Fan, X.; Paul, D.; Kurabayashi, K.; Zellers, E.T. Polymer-coated micro-optofluidic ring resonator detector for a comprehensive two-dimensional gas chromatographic microsystem: $\mu \mathrm{GC} \times$ $\mu \mathrm{GC}-\mu$ OFRR. Analyst 2016, 141, 261-269. [CrossRef] [PubMed]

101. Madani, A.; Harazim, S.M.; Bolaños Quiñones, V.A.; Kleinert, M.; Finn, A.; Ghareh Naz, E.S.; Ma, L.; Schmidt, O.G. Optical microtube cavities monolithically integrated on photonic chips for optofluidic sensing. Opt. Lett. 2017, 42, 486-489. [CrossRef] [PubMed]

102. Smith, E.J.; Xi, W.; Makarov, D.; Mönch, I.; Harazim, S.; Bolaños Quiñones, V.A.; Schmidt, C.K.; Mei, Y.; Sanchez, S.; Schmidt, O.G. Lab-in-a-tube: Ultracompact components for on-chip capture and detection of individual micro-/nanoorganisms. Lab Chip 2012, 12, 1917-1931. [CrossRef] [PubMed]

103. Harazim, S.M.; Bolaños Quiñones, V.A.; Kiravittaya, S.; Sanchez, S.; Schmidt, O.G. Lab-in-a-tube: On-chip integration of glass optofluidic ring resonators for label-free sensing applications. Lab Chip 2012, 12, 2649-2655. [CrossRef] [PubMed]

(C) 2018 by the authors. Licensee MDPI, Basel, Switzerland. This article is an open access article distributed under the terms and conditions of the Creative Commons Attribution (CC BY) license (http://creativecommons.org/licenses/by/4.0/). 